\title{
Arsenic trioxyde in the treatment of HTLV1 associated ATLL
}

\author{
Felipe Suarez ${ }^{1 *}$, Ambroise Marcais ${ }^{1}$, David Ghez², Richard Delarue ${ }^{1}$, Benedicte Deau-Fischer ${ }^{1}$, Charbel Aoun ${ }^{1}$, \\ Flore Sicre de Fontbrune ${ }^{1}$, Laurent Ysebaert ${ }^{3}$, Vahid Asnafi ${ }^{4}$, Daniele Canioni ${ }^{5}$, Hugue deThe ${ }^{6}$, Ali Bazarbachi ${ }^{7}$ \\ Olivier Hermine $8^{*}$
}

From 15th International Conference on Human Retroviruses: HTLV and Related Viruses Leuven and Gembloux, Belgium. 5-8 June 2011

\section{Background}

The prognosis of Adult T-cell leukemia/lymphoma (ATLL) associated with HTLV1 is dismal. The response to conventional chemotherapy ranges between 20 and $70 \%$ and relaspe is constant. Median survival is 8 to 13 months. Chronic and smouldering ATLL have a longer survival, ranging from 18 to 72 months at 5 years. Interferon alpha (IFNa) and AZT combination therapy is effective in acute, chronic and smouldering ATLL, sometimes leading to complete response and has a better prognosis than conventional chemotherapy (5 year survival of $82 \%$ in acute and $100 \%$ in chronic and smouldering forms reaching a complete response). Patients with ATLL/lymphoma do not benefit from IFNa+AZT combination and despite initial response to chemotherapy, all patients eventually relapse. Arsenic trioxyde (AsO3) in combination with IFNa has in vitro activity with a negative regulation of the Tax oncoprotein and leads to apoptosis of HTLV1 transformed lymphocytes. A recent study has showed a benefit in chronic forms of ATLL.

\section{Patients and methods}

11 patients with ATLL were treated with AsO3+IFN combination after a minimum of 1 line of treatment.

\section{Results}

3 patients had ATLL/lymphoma, 3 chronic and 5 acute. All patients had recieved previous therapy with

\footnotetext{
* Correspondence: ohermine@gmail.com

${ }^{1}$ Hématologie Adultes, Groupe Hospitalier Necker - Enfants malades, Paris, France

${ }^{8}$ Hématologie Adultes et Cnrs Umr 8147, Groupe Hospitalier Necker - Enfants malades, Paris, France

Full list of author information is available at the end of the article
}

chemotherapy associated or not with IFNa/AZT combination. At initiation of AsO3, 4 patients were in complete response (3 lymphoma, 1 acute), 2 partial response ( 1 acute, 1 chronic) et 5 in progression ( 3 acute, 2 chronic). 10 patients recieved $\mathrm{AsO} 3$ during 3 to 8 weeks 1 patient progressed 3 days after starting AsO3. Tolerance was acceptable with peripheral neurolopathy $(\mathrm{n}=$ $4)$, hand and foot syndrome $(\mathrm{n}=3)$ et drug eruption $(\mathrm{n}=3$ including 2 toxic epidermal necrolysis). 6 patients died, and all were progressing at time of $\mathrm{AsO} 3$ initiation. 5 patients survived : 3 lymphomas in complete response (25, 31 et 46 months follow-up), 1 acute in complete response (9 months follow-up) and 1 one chronic in partial response (39 months follow-up).

\section{Conclusion}

AsO3 and IFNa combination has an acceptable tolerance profile and seems to be effective in ATLL in consolidation after response to a previous treatment, particularly in lymphoma and chronic forms.

\begin{abstract}
Author details
'Hématologie Adultes, Groupe Hospitalier Necker - Enfants malades, Paris, France. ${ }^{2}$ Hématologie Clinique, Institut Gustave Roussy, Villejuif, France. ${ }^{3}$ Hématologie, CHU Purpan, Toulouse, France. ${ }^{4}$ Hématologie Biologique, Groupe Hospitalier Necker - Enfants malades, Paris, France. ${ }^{5}$ Anatomie Pathologique, Groupe Hospitalier Necker - Enfants malades, Paris, France. ${ }^{6}$ CNRS Hôpital saint Louis, Paris, France. ${ }^{7}$ Hematology - Internal Medicine, American University Hospital, Beyrout, Liban. ${ }^{8}$ Hématologie Adultes et Cnrs Umr 8147, Groupe Hospitalier Necker - Enfants malades, Paris, France.
\end{abstract}

Published: 6 June 2011

doi:10.1186/1742-4690-8-S1-A59

Cite this article as: Suarez et al:: Arsenic trioxyde in the treatment of HTLV1 associated ATLL. Retrovirology 2011 8(Suppl 1):A59.

\section{() Biomed Central}

(c) 2011 Suarez et al; licensee BioMed Central Ltd. This is an open access article distributed under the terms of the Creative Commons Attribution License (http://creativecommons.org/licenses/by/2.0), which permits unrestricted use, distribution, and reproduction in any medium, provided the original work is properly cited. 